\title{
Erratum to: Les enjeux de la jurilinguistique et de la juritraductologie
}

\author{
Anne Wagner · Jean-Claude Gémar
}

Published online: 8 February 2015

(C) Springer Science+Business Media Dordrecht 2015

\section{Erratum to: Int J Semiot Law \\ DOI 10.1007/s11196-015-9405-1}

Assurance de la qualité en traduction juridique: l'évaluation du processus, de la compétence et du produit dans la quête de l'équivalence.

Le professeur Prieto Ramos propose un modèle holistique pour assurer la qualité de l'évaluation en traduction juridique. Fondée sur un cadre fonctionnaliste de la prise de décision, cette démarche passe par l'établissement d'une stratégie d'adéquation basée sur les paramètres juridiques et contextuels impliqués dans le processus de la traduction, de son produit au stade de l'auto-révision et de l'évaluation, et dans la définition des critères d'évaluation et de la compétence attendus des traducteurs et des réviseurs. Ce modèle d'évaluation de la qualité devrait permettre d'améliorer la prédictibilité tout en réduisant la subjectivité et de hausser les standards de la pratique professionnelle de la traduction.

The online version of the original article can be found under doi:10.1007/s11196-015-9405-1.

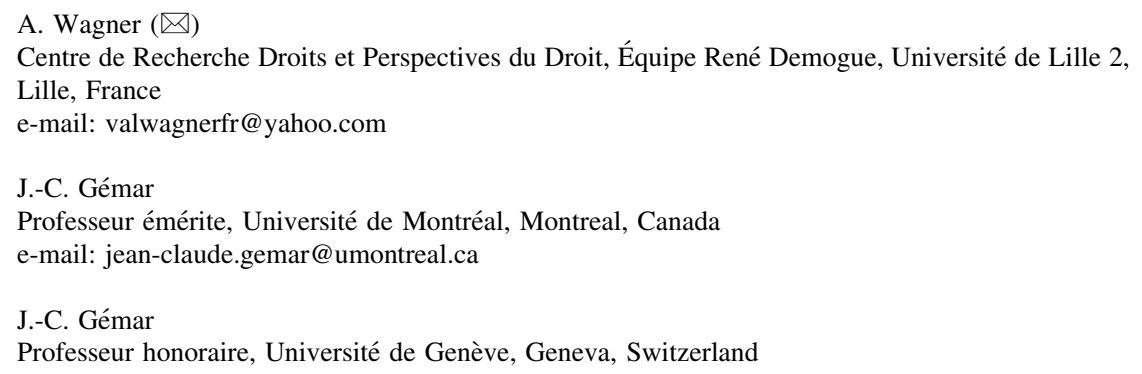

